\title{
Reappraisal of linoleic acid requirement of the young infant, with particular regard to use of modified cows' milk formulae
}

\author{
D. J. NAISMITH, SUSAN P. DEEPROSE, G. SUPRAMANIAM, AND M. J. H. WILliAMS
}

From the Department of Nutrition, Queen Elizabeth College, and the Paediatric Unit, St Mary's Hospital Medical School, London

SUMmaRY Most infants in the UK are bottle fed with cows' milk formulae that are alleged to provide less than the minimum requirement for linoleic acid, i.e. $1 \%$ of the total dietary energy. 20 term infants fed solely on a modified cows' milk formula that provided $0.55 \%$ of the energy from linoleic acid were therefore examined for evidence of deficiency. Rates of growth in length and weight, measured during the first 3 months of life, were identical with those of 20 wholly breast-fed infants. Voluntary food intakes ( $\mathrm{kcal} / \mathrm{kg}$ per day) followed the normal pattern. The fatty acid composition of the plasma lipids showed changes characteristic of a low intake of linoleic acid, but triene:tetraene ratios did not indicate a deficiency state, and clinical signs of deficiency were not observed. These findings suggest that the requirement for linoleic acid is substantially less than was formerly believed. The small amount of $\alpha$-linolenic acid present in cows' milk may however exert a sparing effect on linoleic acid.

The experiments of Hansen and his colleagues (Adam et al., 1958; Hansen et al., 1958; Wiese et al., 1958) clearly demonstrated that the human infant has a specific requirement for linoleic acid (18:2, $\mathrm{n}$-6). Infants who were fed a skim-milk formula in which linoleic acid provided $<0.1 \%$ of the total energy developed a deficiency syndrome, the main features of which were (a) a reduction in the plasma concentration of linoleic acid and arachidonic acid $(20: 4, n-6)$ associated with an increase in the concentration of a triene; (b) impairment of energy use, shown by a pronounced rise in voluntary food consumption which was detected within 1-2 weeks; and (c) a characteristic dermatosis, a dry scaly thickened skin, which was apparent after 1-3 months of feeding. All symptoms disappeared promptly on treatment with the ethyl ester of linoleic acid, the so-called 'essential fatty acid'.

In the body, linoleic acid undergoes alternating desaturation and chain elongation to produce its metabolically active derivative arachidonic acid. This process is not, however, confined to linoleic acid, but high concentrations of linoleic acid in the tissues appear to suppress the desaturation and chain elongation of other fatty acids. When the concen-

Received 10 February 1978 tration of linoleic acid falls, the monoene oleic acid $(18: 1, \mathrm{n}-9)$ which may be synthesised from carbohydrate, is converted to the triene that was detected by Hansen and later identified as eicosatrienoic acid $(20: 3, n-9)$ by Fulco and Mead (1959). The presence of this fatty acid in significant amounts is taken to indicate a suboptimal intake of linoleic acid. It has been observed that clinical symptoms of deficiency appear when the ratio of eicosatrienoic acid to arachidonic acid in the plasma lipids, the so-called triene:tetraene ratio, exceeds 0.4 (Holman et al., 1964), and so this value is generally regarded as the upper limit of normality.

From the results of his studies, Hansen suggested that the minimum requirement for linoleic acid would represent $1 \%$ of the total dietary energy, although he did state that symptoms of deficiency had not been described in infants when fed cows' milk formulae that usually provide somewhat less. He further suggested that an optimal intake might well be the linoleic acid content of the milk of mothers eating the average American diet-approximately $4 \%$ of the total energy. During the last two decades these views have not been seriously challenged, although advances made in the techniques of lipid analysis alone would justify a re-evaluation. In the few studies in which the effects of feeding cows' 
milk on plasma lipid composition have been measured, the numbers of subjects have been very small, the conditions of the experiments have been poorly defined, and the results conflicting (Woodruff et al., 1964; Holman et al., 1965; Pikaar and Fernandes, 1966).

We therefore sought evidence of linoleic acid deficiency in 20 infants fed solely on a commercially available full-cream cows' milk formula during the first 3 months of life.

\section{Materials and methods}

Mothers were invited to participate in the study a few days after delivery of their infants in the maternity wards of St Mary's Hospital Medical School. The subjects chosen had decided before their infants were born either to breast feed for at least 3 months, or to bottle feed. All were primiparous as it was thought that mothers unencumbered with other children might cope more easily with the recording of feeds and the repeated intrusions of the investigators. Their ages ranged from 18 to 32 , they had normal antenatal histories, and their infants were born between 38 and 42 weeks' gestation with birthweights $>2.5 \mathrm{~kg}$.

Twenty infants, 10 boys and 10 girls, were fed solely on artificial milk for 14 weeks. A few were occasionally given small amounts of orange juice, although the formula itself provided adequate amounts of ascorbic acid. Their mean birthweight was $3.60 \mathrm{~kg} .7$ infants, with a mean birthweight of $3.46 \mathrm{~kg}$, received breast milk only for 14 weeks and acted as controls for the biochemical tests. For comparison of rates of growth, however, we used data from an earlier investigation (Ritchie and Naismith, 1975) in which 20 infants (again 10 boys and 10 girls) were wholly breast fed for the same length of time. Their mean birthweight was $3.54 \mathrm{~kg}$.

Measurements of the infants' weights and lengths were made in the home at 10 days postpartum and at fortnightly intervals thereafter for a further 12 weeks. Length was measured by the procedure of Tanner et al. (1966); weight was measured to the nearest $20 \mathrm{~g}$ using a Salter spring balance and a cradle constructed for the purpose. The values were immediately plotted on standard growth charts (Tanner and Whitehouse, 1973) and compared with the previous recorded value so that any discrepancy could be verified by repeating the measurement. Mothers intending to bottle feed their infants were given a supply of the artificial milk (Glaxo Complete Formula) on leaving hospital, and this was replenished when visits were made to their homes. Before departure, the infants had received a fullcream milk formula in the hospital.
Food intakes of the bottle-fed infants were calculated from records kept for one week at the beginning of the study, and again at 28-day intervals. Thus 4 measurements of food consumption were made. On each occasion, 2 new packets of food were used for the 7-day measured food intake, the unused food being weighed by the investigator. Feeds were prepared according to the manufacturer's instructions, and the number and volume of the feeds consumed were recorded by the mother in specially prepared food diaries, together with the intake of fruit juices, the only other foods permitted, and an estimate of food lost by regurgitation. As a further check, at the start of each 7-day period, the mothers put 4 levelled scoops of the powder into a polyethylene bag to be weighed in the laboratory. Although variation in making up the feeds was considerable, each mother was found to be surprisingly consistent in her measurements of the milk. Total energy intakes of the infants were calculated using analytical data supplied by the food manufacturer.

At the end of the study the infants were examined for clinical signs of linoleic acid deficiency, and a heel-prick blood sample was taken for analysis of the plasma total lipids by gas-liquid chromatography. Lithium heparin was used as anticoagulant. The fatty acid composition of the lipids of the milk powder and of breast milk was also determined.

Lipids were extracted from the plasma with a 2:1 (v/v) mixture of chloroform and methanol, and nonlipid contaminants were removed by solvent partitioning (Folch et al., 1957). After saponification of the total lipid extract, the fatty acids were converted to methyl esters by treatment with boron trifluoride reagent (Morrison and Smith, 1964) and separated at $180^{\circ} \mathrm{C}$ in a $1.5 \mathrm{~m} \times 6.4 \mathrm{~mm}$ glass column packed with $100 \mathrm{~g} / \mathrm{kg}$ PEGA on Chromosorb W (100-120-mesh) AW/DMCS. A Pye-Unicam 104 chromatograph fitted with a hydrogen flame ionisation detector was used, the methyl esters being identified by comparison with authentic and secondary reference standards (Ackman, 1969). A special standard for eicosatrienoic acid (20:3, n-9) was prepared from the plasma of rats made deficient in linoleic acid. Lipids extracted from breast milk were analysed by a combination of silver nitrate chromatography and gas-liquid chromatography using three different stationary phases-PEGA, EGSS-X, and EGSS-Y (Sanders, 1977).

Cows' milk fat is more complex in composition than is human milk fat because it contains many positional and geometric isomers of the monounsaturated and polyunsaturated fatty acids, products of biohydrogenation in the rumen of the cow. Complete separation of the biologically active form of linoleic acid (cis-cis 18:2, n-6) from its isomers 
cannot be achieved by conventional gas-liquid chromatography alone. Preliminary fractionation of the methyl esters by silver nitrate thin layer chromatography was used to remove the geometric isomers (cis-trans and trans-trans conjugated dienes) from the mixture. Two major positional isomers of cis-cis linoleic acid were then separated at $160^{\circ} \mathrm{C}$ on a $3.0 \mathrm{~m} \times 6.4 \mathrm{~mm}$ glass column packed with $80 \mathrm{~g} / \mathrm{kg}$ Silar 10C on Chromosorb W (100-120 mesh) AW/DMCS at a carrier-gas flow rate of $10 \mathrm{ml} / \mathrm{min}$. The major component, identified by mass spectrometry of the trimethylsilyloxy derivatives, was $18: 2$, n-6.

Values stated by the manufacturer for fat $(19 \mathrm{~g} /$ $100 \mathrm{~g}$ milk formula) and energy (470 kcal/100 g; $1.96 \mathrm{MJ} / 100 \mathrm{~g}$ ) were used in our calculations, and a factor of 0.95 to allow for non-fatty acid lipid components. For statistical evaluation of the results, Student's $t$ test or, where appropriate, Student's $t$ test for related samples, was used.

\section{Results}

Despite considerable efforts made to select subjects who might reasonably be expected to complete the study, the drop-out rate was approximately $40 \%$. The main factor contributing to this high rate of failure was the reluctance of mothers to withhold solid foods until the infant was 3 months.

Analyses of midstream samples of breast milk supplied by the 7 mothers after 3 months of lactation showed little variation in the fatty acid composition. Linoleic acid $(18: 2, n-6)$ made up on average $6.9 \%$ of the total fatty acids, a value similar to that found for 5 pooled samples of breast milk obtained from different areas of the UK (DHSS, 1977). The fat and energy content of the milks were not measured, but if mean values from the report of the Department of Health and Social Security (1977) on human milk composition are used, linoleic acid would contribute $3.7 \%$ of the total energy, a figure that compares favourably with the 'optimum' intake recommended by Hansen and his colleagues (Wiese et al., 1958).

Fat extracted from the batch of the milk formula that was used in the investigation was found to contain $1.6 \%$ of linoleic acid (cis-cis 18:2, n-6). Using this value it was calculated that linoleic acid could account for no more than $0.55 \%$ of the total energy in this product.

The results of measurements of rates of growth in weight and in length, averaged for the 14 weeks, are presented in Table 1 . No differences were found between the breast-fed infants and those receiving the milk formula low in linoleic acid.
Table 1 Rates of growth in weight and in length of breast-fed and bottle-fed infants, measured over 14 weeks: mean values $\pm S E M$

\begin{tabular}{llllll}
\hline & \multicolumn{2}{l}{ Boys $(n=10)$} & \multicolumn{2}{l}{$\operatorname{Girls}(n=10)$} \\
\cline { 2 - 3 } \cline { 5 - 6 } & g/day & mm/day & & g/day & mm/day \\
\hline Breast fed & $27 \cdot 1 \pm 1.57$ & $1 \cdot 09 \pm 0.04$ & & $24.8 \pm 1.77$ & $1.06 \pm 0.06$ \\
Bottle fed & $26.9 \pm 1.92$ & $1.17 \pm 0.06$ & & $25.0 \pm 1.23$ & $1 \cdot 12 \pm 0.08$ \\
\hline
\end{tabular}

In the young infant, voluntary energy intake is known to fall steadily from about $120 \mathrm{kcal} / \mathrm{kg}$ $(0.50 \mathrm{MJ} / \mathrm{kg})$ per day during the first month to 105 $\mathrm{kcal} / \mathrm{kg}(0.44 \mathrm{MJ} / \mathrm{kg})$ per day at 3 months (Beal, 1970; Fomon et al., 1971). In the present study, energy intake was found to vary greatly among the infants, as indicated by the standard error of the mean (Table 2), but was consistent for individuals. During the period of study, the normal gradual decline in energy intake, expressed in relation to body weight, was observed.

In Table 3 are summarised the results of the analyses of fasting blood samples from breast- and bottle-fed infants. In the latter group, changes in the proportions of the major fatty acids that are characteristic of a low intake of linoleic acid were observed. In comparison with values for the breast-fed controls, linoleic acid (18:2, n-6) and its metabolite arachidonic acid (20:4, n-6) were much reduced, and eicosatrienoic acid (20:3, n-9) was greatly increased. However, in none of the infants that had received the cows' milk formula did the triene:tetraene ratio exceed $0 \cdot 4$.

Clinical examination of the subjects at 3 months provided no evidence of linoleic acid deficiency. One bottle-fed infant suffered from a severe rash, mainly on the face, trunk, and creases of the thighs. The rash was not typical of infantile eczema or sebhorreic dermatitis, and persisted after a filled milk rich in linoleic acid was substituted for the cows' milk formula at the end of the experimental period. This suggested that linoleic acid deficiency was not the cause, a conclusion that was confirmed by the analysis of the infant's plasma lipids; the triene: tetraene ratio was $0 \cdot 26$.

Table 2 Energy intakes of 20 infants fed a cows' milk formula low in linoleic acid; mean values $\pm S E M$

\begin{tabular}{lcccc}
\hline & 2 weeks & 6 weeks & 10 weeks & 14 weeks \\
\hline $\begin{array}{l}\text { Daily energy } \\
\text { intake } \\
\mathrm{kcal} / \mathrm{kg}\end{array}$ & $114 \pm 5.6$ & $110 \pm 4.2$ & $105 \pm 3.0$ & $105 \pm 4.3^{*}$ \\
$\mathrm{MJ} / \mathrm{kg}$ & $0.48 \pm 0.023$ & $0.46 \pm 0.017$ & $0.44 \pm 0.012$ & $0.44 \pm 0.018$ \\
\hline
\end{tabular}

*Value differs from that found at 2 weeks: $0.02<\mathrm{P}<0.05$. 
Table 3 Fatty acid composition of total plasma lipids in breast-and bottle-fed infants: values, calculated as $\mathrm{g} / 100 \mathrm{~g}$ total fatty acids, are shown as mean $\pm S E M$

\begin{tabular}{|c|c|c|c|}
\hline Fatty acid & $\begin{array}{l}\text { Breast fed } \\
(n=7)\end{array}$ & $\begin{array}{l}\text { Bottle fed } \\
(n=20)\end{array}$ & $P$ \\
\hline $\begin{array}{l}12: 0 \\
14: 0 \\
16: 0 \\
16: 1 \\
18: 0 \\
18: 1 \\
18: 2(n-6) \\
18: 3(n-3) \\
18: 3(n-6) \\
20: 0 \\
20: 3(n-6) \\
20: 3(n-9) \\
20: 4(n-6) \\
22: 0\end{array}$ & $\begin{array}{r}1 \cdot 23 \pm 0.39 \\
3.46 \pm 0.33 \\
24 \cdot 50 \pm 0.78 \\
4 \cdot 34 \pm 0.61 \\
8 \cdot 80 \pm 0.46 \\
29 \cdot 30 \pm 1 \cdot 43 \\
17 \cdot 20 \pm 0.89 \\
1 \cdot 24 \pm 0.27 \\
0.34 \pm 0.13 \\
0.70 \pm 0.06 \\
1 \cdot 17 \pm 0.19 \\
0.15 \pm 0.02 \\
5.90 \pm 0.82 \\
0.53 \pm 0.11\end{array}$ & $\begin{array}{r}0.70 \pm 0.07 \\
4.01 \pm 0.36 \\
26.90 \pm 0.52 \\
5 \cdot 84 \pm 0.18 \\
8.38 \pm 0.32 \\
35 \cdot 70 \pm 0.74 \\
10.00 \pm 0.57 \\
0.90 \pm 0.10 \\
0.40 \pm 0.06 \\
0.41 \pm 0.05 \\
0.96 \pm 0.07 \\
0.66 \pm 0.06 \\
2.93 \pm 0.18 \\
0.71 \pm 0.07\end{array}$ & $\begin{array}{c}\text { NS } \\
\text { NS } \\
<0.02 \\
<0.05 \\
\text { NS } \\
<0.01 \\
<0.001 \\
\text { NS } \\
\text { NS } \\
<0.01 \\
\text { NS } \\
<0.001 \\
<0.01 \\
\text { NS }\end{array}$ \\
\hline Triene/tetraene & $0.028 \pm 0.005$ & $0.222 \pm 0.017$ & $<0.001$ \\
\hline
\end{tabular}

\section{Discussion}

A dietary deficiency of linoleic acid in adults is unlikely to occur. Even the meanest cereal-based diet contains between 5 and $10 \%$ of vegetable fats, and therefore provides an adequate intake of linoleic acid. It is the infant population that could be at risk, but only when artificial feeding is adopted. The concentration of linoleic acid in breast milk is by no means constant, being readily influenced by the maternal diet. In well-nourished mothers, values for the linoleic acid content of milk fat ranging from 6.3 to $31.7 \%$ (Read et al., 1965; Sanders, 1977) have been reported. Nevertheless, the proportion of the total energy derived from linoleic acid is invariably in excess of $1.0 \%$.

There is only one report of naturally occurring linoleic acid deficiency in infants (Naismith, 1973), although there have been several accounts of deficiency induced by prolonged intravenous feeding with preparations lacking in fat (Caldwell et al., 1972; Paulsrud et al., 1972; White et al., 1973).

Cows' milk fat contains between 0.8 and $1.9 \%$ of linoleic acid (Hall, 1970). If the milk is modified, usually by the addition of carbohydrate, in order to reduce its high osmolality, the proportion of fat is reduced, and consequently so is the contribution made by linoleic acid to the total dietary energy. The infant milk used in the present investigation was cows' milk modified by the addition of maltodextrin. The risk of linoleic acid deficiency arising from the use of modified cows' milk formulae is, however, short lived. The present practice in the UK is to introduce cereal-based solids into the infant's diet before age 3 months (Department of Health and Social Security, 1974) which promptly redresses the imbalance of polyunsaturated fatty acids in the plasma lipids (Pikaar and Fernandes, 1966). For this reason we regarded 3 months as a realistic period for evaluating the effects of an intake of linoleic acid below the accepted minimum believed to be compatible with good health.

Our failure to observe skin changes in the bottlefed infants was not surprising; the dermatosis characteristic of linoleic acid deficiency was produced by Hansen et al. (1958) only after many weeks of feeding a skim-milk formula. Fosbrooke and Wharton (1975) likewise failed to detect skin changes in 15 low birthweight infants who were fed for 3 months a formula providing approximately $0.5 \%$ of the energy from linoleic acid. Their infants would have had the additional disadvantage of low body fat reserves of linoleic acid. In the experiments of Hansen and his colleagues the metabolic response was more rapid, a striking rise in voluntary food intake occurring within 2 weeks. In the present study, no abnormality in the rate of growth or deviation from the normal pattern of food consumption was evident in the artificially-fed infants.

The changes in the plasma lipid composition that result from the withdrawal of linoleic acid from the diet are immediate. Triene:tetraene ratios greater than 0.4 have been found within a few days of initiating parenteral feeding with fat-free solutions (Paulsrud et al., 1972). In none of our infants was this value exceeded, even after 14 weeks of feeding with the modified cows' milk formula. The triene: tetraene ratio may not, however, have been determined solely by the intake of linoleic acid and its derivative arachidonic acid. The addition of $\alpha$ linolenic acid $(18: 3, n-3)$ to the diet of rats made deficient in linoleic acid has been shown to depress the synthesis of eicosatrienoic acid, and thus to reduce the plasma triene:tetraene ratio (Morhauer and Holman, 1963). Furthermore, $\alpha$-linolenic acid was found to stimulate growth and reduce the severity of the dermal symptoms. Although the formula we used contained only traces of arachidonic acid it did contain appreciable amounts of $\alpha$-linolenic acid and its long-chain derivatives-approximately $1 \%$ of the total fatty acids.

In conclusion, therefore, it cannot be stated unequivocally that the requirement of the human infant for linoleic acid can be satisfied by an intake representing $0.55 \%$ of the total energy, although this may well be so. It can, however, be stated that a modified cows' milk formula providing this minute proportion of the total energy from linoleic acid, with a similar contribution from $\alpha$-linolenic acid and its derivatives, is sufficient to prevent the clinical, metabolic, and biochemical manifestations of essential fatty acid deficiency. 
We thank Professors R. W. Beard and T. E. Oppé of St Mary's Hospital Medical School for cooperation, the Department of Health and Social Security for a research grant, and Glaxo Ltd for providing the infant food.

\section{References}

Ackman, R. G. (1969). Gas-liquid chromatography of fatty acids and esters. In Methods in Enzymology: Lipids, volume fourteen, p. 329. Edited by J. M. Lowenstein. Academic Press: New York.

Adam, D. J. D., Hansen, A. E., and Wiese, H. F. (1958). Essential fatty acids in infant nutrition. II. Effect of linoleic acid on caloric intake. Journal of Nutrition, 66, 555-564.

Beal, V. A. (1970). In Human Growth and Development, p. 63. Edited by R. W. McCarrow. Thomas: Springfield.

Caldwell, M. D., Jonsson, H. T., and Othersen, H. B. Jr (1972). Essential fatty acid deficiency in an infant receiving prolonged parenteral alimentation. Journal of Pediatrics, 81, 894-898.

Department of Health and Social Security (1974). Present-day Practice in Infant Feeding. Report on Health and Social Subjects No. 9. HMSO: London.

Department of Health and Social Security (1977). Composition of Mature Human Milk. Report on Health and Social Subjects No. 12. HMSO: London.

Folch, J., Lees, M., and Sloane-Stanley, G. H. (1957). A simple method for the isolation and purification of total lipids from animal tissues. Journal of Biological Chemistry, 226, 497-509.

Fomon, S. J., Thomas, L. N., Filer, L. J. Jr, Ziegler, E. E., and Leonard, M. T. (1971). Food consumption and growth of normal infants fed milk-based formulas. Acta paediatrica Scandinavica, Supplement 223.

Fosbrooke, A. S., and Wharton, B. A. (1975). 'Added lactose' and 'added sucrose' cows' milk formulae in nutrition of low birthweight babies. Archives of Disease in Childhood, 50, 409-418.

Fulco, A. J., and Mead, J. F. (1959). Metabolism of essential fatty acids. VIII. Origin of $5,8,11$-eicosatrienoic acid in the fat-deficient rat. Journal of Biological Chemistry, 234, 1411-1416.

Hall, A. J. (1970). Seasonal and regional variations in the fatty acid composition of milk fat. Dairy Industry, 35, 20-25.

Hansen, A. E., Haggard, M. E., Boelsche, A. N., Adam, D. J. D., and Wiese, H. F. (1958). Essential fatty acids in infant nutrition. III. Clinical manifestations of linoleic acid deficiency. Journal of Nutrition, 66, 565-576.

Holman, R. T., Caster, W. O., and Wiese, H. F. (1964). The essential fatty acid requirement of infants and the assessment of their dietary intake of linoleate by serum fatty acid analysis. American Journal of Clinical Nutrition, 14, 70-75.
Holman, R. T., Hayes, H. W., Rinne, A., and Söderhjelm,. L (1965). Polyunsaturated fatty acids in serum of infants fed breast milk or cows' milk. Acta paediatrica Scandinavica, 54, 573-577.

Morhauer, H., and Holman, R. T. (1963). The effect of dose level of essential fatty acids upon fatty acid composition of the rat liver. Journal of Lipid Research, 4, 151-159.

Morrison, W. R., and Smith, L. M. (1964). Preparation of fatty acid methyl esters and dimethylacetals from lipids with boron fluoride-methanol. Journal of Lipid Research, 5, 600-608.

Naismith, D. J. (1973). Kwashiorkor in Western Nigeria: a study of traditional weaning foods, with particular reference to energy and linoleic acid. British Journal of Nutrition, 30, 567-576.

Paulsrud, J. R., Pensler, L., Whitten, C. F., Stewart, S., and Holman, R. T. (1972). Essential fatty acid deficiency in infants induced by fat-free intravenous feeding. American Journal of Clinical Nutrition, 25, 897-904.

Pikaar, N. A., and Fernandes, J. (1966). Influence of different types of dietary fat on the fatty acid composition of some serum lipid fractions in infants and children. American Journal of Clinical Nutrition, 19, 194-204.

Read, W. W. C., Lutz, P. G., and Tashjian, A. (1965). Human milk lipids. II. The influence of dietary carbohydrates and fat on the fatty acids of mature milk. A study in four ethnic groups. American Journal of Clinical Nutrition, 17, 180-183.

Ritchie, C. D., and Naismith, D. J. (1975). A comparison of growth in wholly breast-fed infants and in artificially fed infants. Proceedings of the Nutrition Society, 34, 118A.

Sanders, T. A. B. (1977). The composition of red cell lipid and adipose tissue in vegans, vegetarians, and omnivores. $\mathrm{PhD}$ thesis, University of London.

Tanner, J. M., and Whitehouse, R. H. (1973). Height and weight charts from birth to 5 years allowing for length of gestation: for use in infant welfare clinics. Archives of Disease in Childhood, 48, 786-789.

Tanner, J. M., Whitehouse, R. H., and Takaishi, M. (1966). Standards from birth to maturity for height, weight, height velocity, and weight velocity: British children, 1965. Part I. Archives of Disease in Childhood, 41, 454-471.

White, H. B. Jr, Turner, M. D., Turner, A. C., and Miller R. C. (1973). Blood lipid alterations in infants receiving intravenous fat-free alimentation. Journal of Pediatrics, 83, 305-313.

Wiese, H. F., Hansen, A. E., and Adam, D. J. D. (1958). Essential fatty acids in infant nutrition. I. Linoleic acid requirement in terms of serum di-, tri-, and tetraenoic acid levels. Journal of Nutrition, 66, 345-360.

Woodruff, C. W., Bailey, M. C., Davis, J. T., Rogers, N., and Coniglio, J. G. (1964). Serum lipids in breast fed infants and in infants fed evaporated milk. American Journal of Clinical Nutrition, 14, 83-90.

Correspondence to Dr D. J. Naismith, Department of Nutrition, Queen Elizabeth College, Atkins Building, Campden Hill, London W8 7AH. 